\title{
Quantifying Anecdotes: Google Search Data and Political Developments in Egypt
}

Gabriel Koehler-Derrick, United States Military Academy, West Point

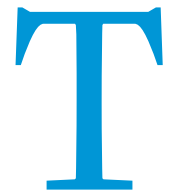
he events of 2011 transformed the politics of the Arab world. In just under 12 months, dictators fell in three countries: Tunisia, Egypt, and Libya. In Bahrain, Yemen, and Syria, protests and violence continued throughout 2012 to shake what were once assumed to be the solid foundations of long-standing autocratic regimes. Although it is too soon to assess the outcome of these events, one immediate consequence is clear: the empowerment of public opinion in Arab politics. For the first time in more than 50 years, the voices of average Tunisians, Egyptians, and Libyans can directly influence political outcomes. This shift may yet prove to be temporary, but its importance in driving current events cannot be discounted.

These political shifts and the subsequent empowerment of public opinion have outpaced regional polling efforts, injecting further uncertainty into an already unpredictable period of change. Discrepancies between electoral results and polling outcomes prior to both the parliamentary and presidential elections in Egypt are illustrative of this challenging dynamic (Abu Dhabi Gallup 2011; al-Ahram Online 2012; Telhami 2011). In 2011 and 2012, politicians campaigned and Egyptians voted without reliable measures of public attitudes toward the various parties and individual candidates. This situation helps to explain, at least in part, the shock in both the United States and Egypt at the success of the Salafi Hezb al-Nour party in the first round of parliamentary elections in 2011 and Ahmed Shafiq in the presidential elections of 2012. In the two years since the Egyptian revolution, several local organizations have attempted to initiate regular polling efforts that inform the public and the candidates about the opinions of Egyptian society ('Abd al-Gawad et al. 2012; al-Ahram 2011; DEDI 2011; Thawra Stats 2011), but many challenges clearly will have to be overcome before reliable polling becomes a routine part of Egyptian politics. ${ }^{1}$

The increasing use of the Internet to search for information about candidates, parties, and events, however, suggests an intriguing alternative: that political scientists might use online search data to enhance conventional studies of public opinion in places like Egypt where traditional sources of such data are absent or unreliable. In the following sections, I review how search data has been used in the past, examine the advantages and disadvantages of using search data to gauge public opinion during periods of rapid transition, and illustrate these dynamics by examining how search data and the concept of "attentiveness" help to shed light on the battle for framing and narrative control in post-revolutionary Egypt.

\section{PREVIOUS APPLICATIONS OF SEARCH DATA}

Previous work has established the utility of Internet search data in highly connected societies. Researchers in economics and public health have been using Google's "database of intentions" 2 for several years to further our understanding of phenomena as varied as the spread of swine flu and other illnesses (Carneiro and Mylonakis 2009; Ginsberg et al. 2009), the retail prices of cars and homes (Choi and Varian 2009), and revenues for video games and movies (Goel et al. 2010). These studies are based on a simple observation: frequently a high correlation exists between online searches and offline outcomes. That discrepancies may exist between online searches and some events offline, or that only a fraction of the billions of searches in any given day pertain to a term of interest, is not a major challenge for these studies. To date, these discrepancies have been a limited concern because most researchers who utilize search data are concerned with developments in North America, East Asia, and Europe-regions characterized by high rates of Internet penetration. Higher levels of connectivity are crucial because they narrow potential demographic discrepancies between Internet users and the rest of society. ${ }^{3}$

Furthermore, a variety of researchers, particularly in the fields of economics, sociology, and public health, have demonstrated that frequency of search and changes in search volume can be validated by more conventional measures of attitudes and behavior (Newig 2004; Ripberger 2011). For example, scholars who have looked at search data as a proxy tool for measuring public opinion have found high degrees of correlation with "Most Important Problem" (MIP) surveys (Mellon 2011; Scharkow and Vogelgesang 2011). Not surprisingly, researchers also found search data to be an especially useful tool for capturing behavior or attitudes that respondents might be hesitant to express to an interviewer with a clipboard (Stephens-Davidowitz 2012). Whereas the use of Internet data is far more limited within political science, the contributions to this symposium, as well as by other prominent researchers, suggest the significant potential of Internet data even in authoritarian and restrictive research environments (Chestnut-Greitens 2013, this issue; Hassanpour 2011; King, Pan, and Roberts 2012).

\section{SEARCH DATA: ADVANTAGES}

What use does search data have in a country like Egypt, where access to the Internet is far more limited than in East Asia, Europe, or North America?4 At least three significant facets of search data make it a promising analytical tool for highly 
dynamic political environments where traditional survey methods may falter-even if Internet penetration rates in the developing world are much lower than the countries where such techniques have typically been applied before. ${ }^{5}$

\section{Format, Accessibility, and Cost}

Internet search data from Google is free and easy to access. Its measurements are precise and uniform. Except for anomalous circumstances like the Internet blackout in Egypt January 27 to February 2, 2011 (Cowie 2011), researchers will always have access to search data. Reliable access to data is particularly important in a developing country like Egypt where, as one entrepreneur acknowledged, "you are conducting research in a country with no baselines." "Official" statistics in Egypt are often dubious, and even reliable data, when it is available, is frequently in a format that is unwieldy or expensive to digitize. Under these circumstances, a wellmanaged, publically available dataset is a useful asset and far less costly than conventional survey instruments (Granka 2010; Scheitle 2011). ${ }^{7}$

\section{Speed of Data Collection}

Another advantage is that search data is up to the minute. Google's AdWords tool provides a 30-day rolling average of any search term. Google Trends, which provides normalized variations in search trends over time, updates its results, with only a two-day lag and can be filtered by date and location. construct a random sample for their survey so the findings of the poll can be used to generalize about a larger population. ${ }^{11}$ Because no observable "individual" exists in Google's summarized search data, a probability sample cannot be constructed. This makes statistically valid generalizations about the Egyptian population using publically available search data impossible. $^{12}$

\section{Demographic Discrepancies}

In developing countries like Egypt, where Internet penetration levels are relatively low, a second challenge emerges because of the potential for significant demographic discrepancies between Internet users and the rest of the population. For example, a recent survey suggests that Internet users in Egypt are disproportionately young and male, with the 15-34 age group strongly represented online (Insights MENA 2011). These users are also presumably wealthier, more focused in urban areas, and more likely to be literate than the average Egyptian, but no publically available data on the socioeconomic characteristics of Internet users in Egypt definitively confirms these assumptions. Finally, whereas surveys typically capture key demographic and political data (race, age, religious identity, political affiliation, etc.), search data, which simply tracks frequency of search terms over time, cannot offer such insights. This makes arguments about causality or controlling for specific demographic features impossible with publically available search data alone.

\section{Search data's most important advantage lies in its sheer volume. As of January 2013 approximately 50 million Google searches are made in Egypt on any given day.}

This is a significant advantage when fast-paced events can often confound efforts to gauge attitudes toward political figures, parties, and developments. ${ }^{8}$

\section{Volume}

Search data's most important advantage lies in its sheer volume. As of January 2013 approximately 32.8 million Google searches are made in Egypt on any given day. ${ }^{9}$ Google is ubiquitous in Egypt, accounting for between $97 \%$ and $98 \%$ of the search market (Global Stats 2012). Google's dominant market share makes Google-derived data an extremely useful tool for identifying trends in search for Egypt's nearly 25 million estimated Internet users who themselves represent an important political constituency as well as a growing segment of Egyptian society (MCIT 2012). ${ }^{10}$

\section{SEARCH DATA: CHALLENGES}

Several significant methodological limitations are inherent in the use of search data.

\section{Probability Sampling}

The most important advantage of surveys over search data concerns representativeness. An experienced research team will

\section{Nuance}

A well-written questionnaire avoids misleading questions, ambiguous language, or focus on overly detailed issues of little relevance to the general public, also known as the "problem of nonattitudes" (Asher 2007). By circumventing these pitfalls of survey design, questionnaires can provide a high degree of resolution on participants' attitudes. For example, surveys typically feature a variety of questions that allow responses to be placed across a spectrum. This creates a far more nuanced set of results even concerning complex topics like the implementation of "hadud" punishments or "views of democracy"-two examples from a Pew Global Attitudes Project survey in Egypt (Pew 2010).

Search data, unlike polling or a survey, cannot provide direct insights into the opinions behind the query. Someone could be searching for Mohammed Elbaradei because they support the former International Atomic Energy Agency (IAEA) head or because they loathe him. This example demonstrates a final challenge of aggregated search data-while spikes in search data are almost always a reflection of actual events, trend lines do not indicate whether this attention is positive or negative. ${ }^{13}$ In other words, rarely are the motives behind any individual search apparent, although more sophisticated technical analysis might help tackle this challenge. 


\section{CASE STUDY: "EGYPT IS NOT TAHRIR"}

"Egypt is not Tahrir or Muhammed Mahmoud Street ..."

$$
\text { -Major General Mukhtar El Mallah }{ }^{14}
$$

The Utility of "Attentiveness:"15 Although search data cannot be used as a proxy measure for intentions, it is a great measure of attention (Ripberger 2011). ${ }^{16}$ Three components of the "attentiveness" concept, as captured by search data, are of immediate interest to political scientists. First, unlike a poll that captures attitudes, search data measures behavior. Second, because searching for something online requires a time commitment, it is also presumably a reflection of genuine interest. Finally, because the person entering the search term is not under observation by a researcher, there are few constraints on what they search (see Stephens-Davidowitz 2012). These three factors are what give the concept of "attentiveness," first developed by Ripberger with regards to search data, its analytical punch. When we use search data, we are examining the aggregate actions of individuals, each at a distinct time and specific location, compelled by their own initiative and interest, searching for a given term or phrase. ${ }^{17}$

Despite remaining methodological challenges to the integration and validation of search data, its advantages, especially when combined with rapidly increasing levels of Internet penetration worldwide, suggest a promising tool for under- underlying logic. Soon after the press conference, slightly different permutations of the phrase were used by the military's supporters, by crowds in regular demonstrations in the Abbasiya neighborhood, and in numerous editorials, Facebook pages, and television interviews (Shadid 2011) ${ }^{19}$ Some commentators subsequently interpreted parliamentary elections results as vindicating General El Mallah's characterization (Shatz 2012).

These anecdotes helped clarify the importance of the debate, yet it was much more challenging to assess which frame predominated Egyptian society as the anniversary of the revolution approached. Events on the ground were far too easy to interpret based on preexisting perceptions. Activists pointed to the huge and peaceful turnout on the anniversary of the revolution as definitive proof of the power and resonance of the revolution, while SCAF officials highlighted rioting after tragedy struck at a soccer match in Port Said in February as evidence that protestors were no better than thugs and opportunists. ${ }^{20}$ Search data, gathered from four different sources are combined in this section to empirically measure these competing frames: Google Trends, which measures search trends over time; Google AdWords, which provides a 30-day rolling average of a given search term; a refined Google search for the period of December 2010 to January 31, 2012, which measures the amount of content available online; and Google Zeitgeist, which tracks the highest emerging search terms in a given

\section{Activists pointed to the huge and peaceful turnout on the anniversary of the revolution as definitive proof of the power and resonance of the revolution, while SCAF officials highlighted rioting after tragedy struck at a soccer match in Port Said in February as evidence that protestors were no better than thugs and opportunists.}

standing the actors and ideas animating society. The following section illustrates how this tool can be applied even in the highly tumultuous politics of Egypt in the aftermath of the "Arab Spring."

Major General Mukhtar El Mallah probably deserves credit for striking the initial blow in what was to become a fiercely contested framing battle between the Supreme Council of the Armed Forces (SCAF) and demonstrators over the legacy of the "January 25 Revolution" that forced former president Hosni Mubarak from power. In September and October, as the first anniversary of the revolution loomed, numerous attempts to discredit the protestors were made, but the framing debate that began in late 2011 was qualitatively different. Speaking at a press conference on November 24, 2011, after violent demonstrations in Mohammed Mahmoud Street, General El Mallah launched a new line of attack: the protestors did not represent the will of Egypt's citizenry, most of whom wanted a return to normalcy. ${ }^{18}$ Instead, he suggested, the protestors were provocateurs whose actions perpetuated chaos and threatened the plan for transition (specifically, the parliamentary elections which were scheduled for the end of the month). Regime apologists, pro-SCAF supporters, and individuals fed up with months of uncertainty readily embraced this phrase and its year. These data cumulatively show that despite the SCAF's concerted effort to discredit ongoing demonstrations, events and figures associated with Tahrir Square and the revolution more broadly continued to captivate the attention of Egyptians online. The results from the first round of the presidential elections in May 2012 support the online evidence by demonstrating strong support for "revolutionary" candidates despite the best efforts of the SCAF to convince Egyptians that the revolution was over.

The unpopularity of President Mubarak and the largely peaceful nature of the protests meant that most Egyptians viewed demonstrators positively. The army's refusal to fire on protestors during the key 18-day period of the revolution, in stark contrast with the police, meant that Egyptians were also overwhelmingly supportive of the military, and initially the SCAF seemed to enjoy widespread support (Pew Global Attitudes, April 25, 2011). However, as street protests continued and occasional violence between demonstrators and security forces flared, evidence of polarization emerged (Younis and Younis 2012). By October and November 2011, as confrontations between protestors and security forces became more frequent, it seemed clear that the demonstrators, an amalgam of movements with few overarching goals now that Mubarak 
Table 1

"Fastest Rising Searches" in Egypt, Saudi Arabia, and United States

\begin{tabular}{llll} 
RANK & \multicolumn{1}{c}{ EGYPT } & \multicolumn{1}{c}{ SAUDI ARABIA } & \multicolumn{1}{c}{ UNITED STATES } \\
\hline 1 & January 25 Revolution & Youtube & Rebecca Black \\
\hline 2 & Midan Tahrir & Facebook & Google Plus \\
\hline 3 & Facebook & $\begin{array}{l}\text { Hafez (allowance for job } \\
\text { seekers in SA) }\end{array}$ & Hurricane Irene \\
\hline 4 & Jokes 2011 & Games & Pinterest \\
\hline 5 & Al Yoom al-Saba (News site) & Twitter & Ryan Dunn \\
\hline 6 & Mubarak's Trial & Sponge Bob & Iphone 5 \\
\hline 7 & Twitter & Al-Jazeera & Casey Anthony \\
\hline 8 & Finance Ministry & Heart-Heart (Song) & Adele \\
\hline 9 & Google Gravity & Al-Arabiya (TV station) & Osama Bin Laden \\
\hline 10 & Forbidden Love (TV Series) & Al-Tasleef Bank & Steve Jobs
\end{tabular}

Source: Google Zeitgeist

was no longer in power, did not have a unified strategy for winning over Egyptian society. The Egyptian military, in contrast, was far more pragmatic in its approach. As the anniversary of the revolution neared, its strategy seemed to broadly focus around a single goal: convincing the Egyptian people that the revolution was over. To achieve their mission, the SCAF sought to limit attention to embarrassing incidents and discredit popular ideas and figures associated with the revolution who continued to advocate for demonstrations and the end of military rule.

Search data from Egypt in 2011 suggests that attention to events in and around Tahrir Square had not vanished as the year came to a close (table 1). Whereas the largest peak in searches directly related to events in the square occurred in late January and early February 2011, Google's Zeitgeist project that captures the fastest-rising search trends in Egypt and other countries reflects the profound influence of political developments on Egyptian search trends. Although more ambiguous as a proxy for prorevolutionary sentiment, total searches for the term "Mubarak" in 2011 exceeded annual searches for the Egyptian pop-star Amr Diab for the first time since Google started publishing normalized search data, and three different peaks for "Mubarak" in mid-February, April, and early August 2011, dwarfed even the sharp spike in searches for the hit 2011 TV series, "Forbidden Love" (figure 1).

Much as the SCAF might have wished otherwise, search data strongly suggested that more than a year after the revolution, events and figures associated with Tahrir Square continued to capture the attention of Egyptians well into 2012.

Google's Zeitgeist tool breaks down individual search terms into categories to facilitate more meaningful comparisons of the top-rising searches in a given year. This data painted a slightly rosier picture for the SCAF. Even considering the tremendous amounts of attention generated by events in Tahrir, the top six searches in the entertainment category, mostly related to pop stars and television shows, far exceeded the total volume of searches in the "individuals" category. High levels of search for figures associated with sports and entertainment might be interpreted as a welcome return to normalcy after a year of political turmoil and upheaval, particularly given the resonance of these figures with the youthful demographic which had been so critical to sustaining the protests.

Nonetheless, Google's Zeitgeist data for the top 10 rising searches pertaining to individuals in the news in 2011 presented further trouble for the SCAF. Not surprisingly, all of these figures were overtly connected with the revolution (table 2). Of the top 10 individual searches only Tamer Ashour, a popular singer, reflected interest in events outside of Tahrir. The other nine were all directly associated with the

\section{Figure 1 \\ Search Trends for "Mubarak" (dark grey) and "Amr Diab" (light grey)}

The number 100 represents the peak search volume. 
Table 2

\section{Top Ten Fastest Rising Searches (People)} Egypt

\begin{tabular}{|c|c|}
\hline RANK & EGYPT \\
\hline 1 & Mubarak (Former President) \\
\hline 2 & $\begin{array}{l}\text { Wa'el Ghonim (Founder of "We Are Khalid Said" Facebook } \\
\text { page) }\end{array}$ \\
\hline 3 & Hishaam al-Gakh (Poet) \\
\hline 4 & $\begin{array}{l}\text { Essam al-Sharif (Former prime minister, supportive of } \\
\text { Tahrir protests) }\end{array}$ \\
\hline 5 & Tamer al-Ashour (Musician) \\
\hline 6 & 'Amr Qatamish (Poet) \\
\hline 7 & Hussein Salem (Corrupt businessman, fled country) \\
\hline 8 & $\begin{array}{l}\text { Ahmed Shehat (Demonstrator, pulled down flag at Israeli } \\
\text { embassy) }\end{array}$ \\
\hline 9 & $\begin{array}{l}\text { Ahmed 'Ez (Industrialist, and longtime associate of } \\
\text { Mubarak family) }\end{array}$ \\
\hline 10 & Gamal Mubarak (son of former president) \\
\hline
\end{tabular}

Source: Google Zeitgeist http://www.googlezeitgeist.com/eu

revolution (table 2). The surge in searches for Mubarak, Hussein Salem, Ahmed 'Az, and Gamal Mubarak are safely interpreted as online manifestations of both the schadenfreude and shock unleashed by the revolution, as each of these previously untouchable figures was put on trial, or in the case of Salem, fled the country. The other newsworthy individuals were either connected with actual events in the square, like Ghonim and al-Sharif, or directly channeled themes from the revolution, like al-Gakh and Qatamish, competitors on an "American Idol" style program for poetry where both drew on events, themes, and figures from the revolution in their performances. ${ }^{21}$

These results strongly suggest that the SCAF's attempts to portray demonstrators in Tahrir as disconnected from the rest of Egypt, as of the end of January 2012, were not effective online. As a statement of fact, General El Malah was correct to assert that protestors in the square did not "represent" all Egyptians and polling at the time suggested that many Egyptians no longer viewed protests as productive (Younis and Younis 2011). Nonetheless,

\section{Figure 2}

if interest in the revolution was failing or if there was no substantive connection between regular Egyptians and demonstrators in Tahrir Square, Internet searches for information about revolutionary figures and developments in Tahrir would not have been sustained at such impressive levels. ${ }^{22}$

Even worse for the SCAF, several prominent failures, including the killings of Coptic demonstrators at Maspiro, the hub of official Egyptian media, the killing and beating of protestors in November and late December 2011, and in early February 2012 the death of approximately 70 fans at as soccer match in Port Said, caused huge surges of online attention. Starting in October of 2011, spikes in searches for the terms "al-jaysh" (the army) and "shuhada" (martyrs) were seen as well as strong levels of correlation between these two terms throughout this crucial period leading up to the first round of parliamentary elections (figure 2). Although there were subsequently substantial diversions in the trend lines, particularly in December and February when there was no direct linkage between the army and the deaths of protestors, the correlation between the search terms "army" and "martyrs" in October and November suggests that at a key moment, millions of Egyptians potentially associated the military and the deaths of innocent protestors. Even more ominously for the SCAF, search trends for the term "martyrs" cuts across the entire country (figure 3$)^{23}$

The absence of reliable survey data from the period of interest makes it difficult to validate these results with more

\section{Search Trends for the Terms "Army" (black) and "Martyrs" (grey)}

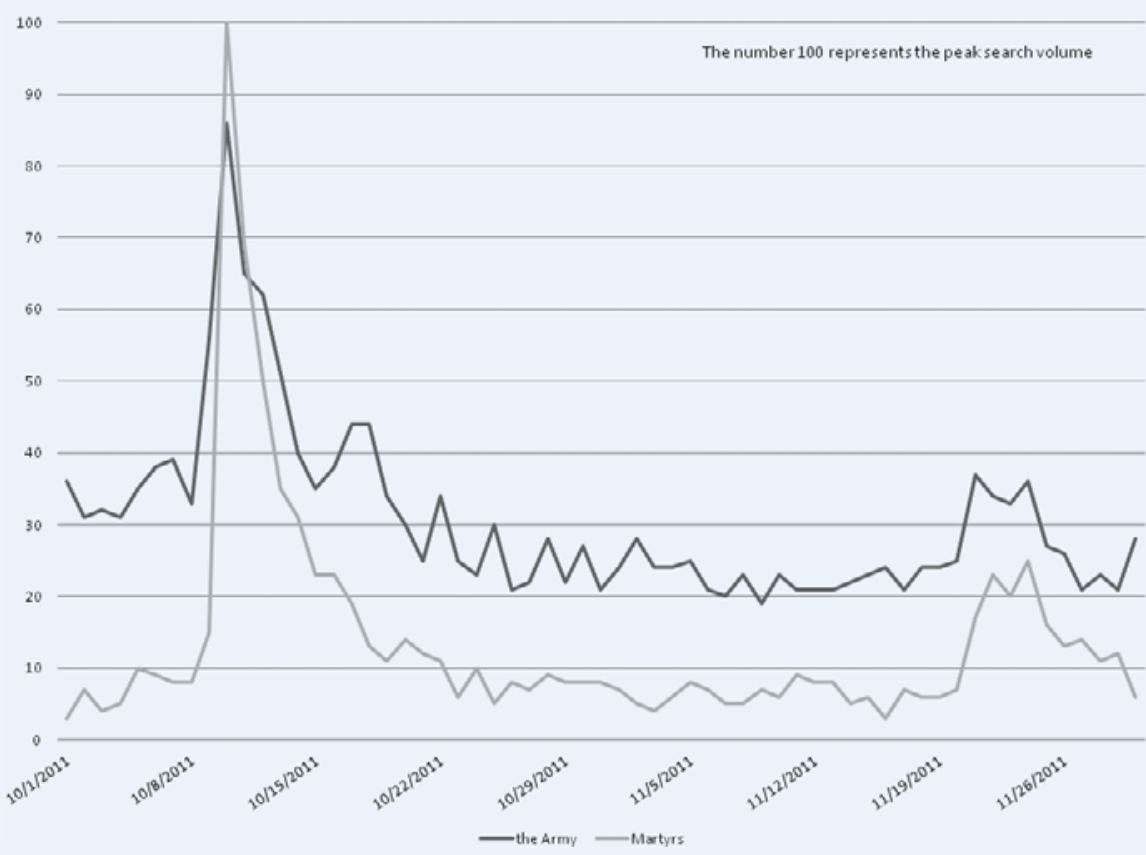

Both Boolean phrases have been adjusted to remove results related to erroneous terms e.g. "Israel" "Libya" or "Gaza." There is a small spike in the search term "army" on October 6-7 which coincides with the National holiday commemorating the October War. The sharp spike on the October 10 coincides with the Maspiro incident. Small spikes in late November coincide with confrontations in downtown Cairo, notably Mohammed Mahmoud Street. 
Figure 3

Geographic Dispersion of Searches for the Term "Martyrs" and Trend Line over Time
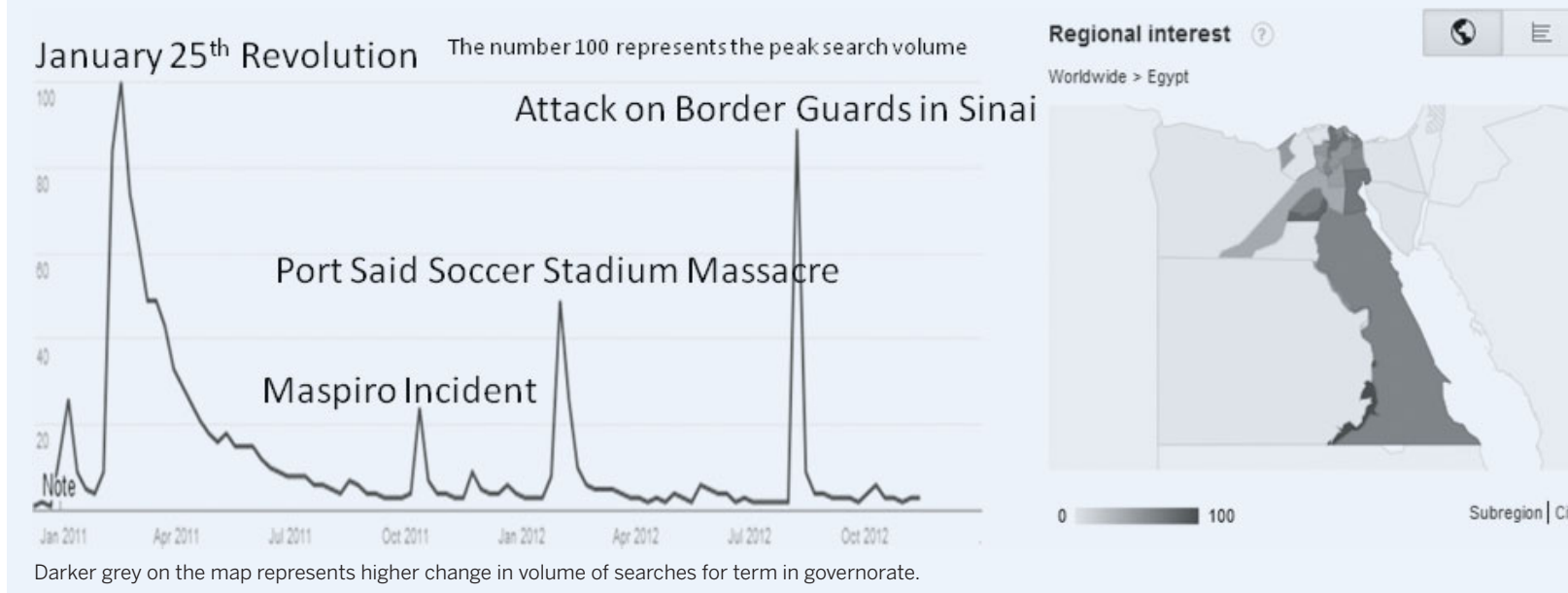

Worldwide > Egypt

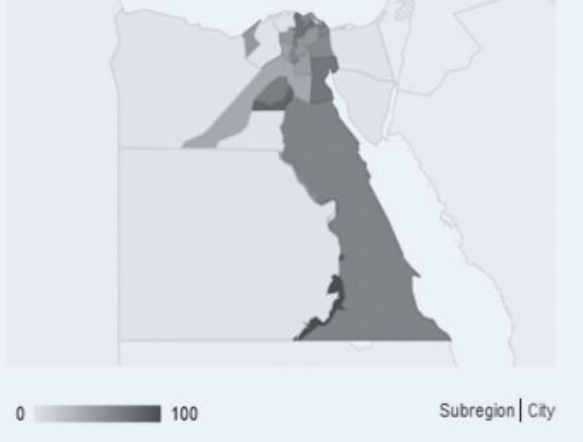

$0 \longrightarrow 100$

Subregion | City

familiar research methods. However, as the presidential campaign got under way in the spring of 2012, SCAF's attempts to paint demonstrators as disconnected from Egyptian society, and the revolution as concluded, had clearly failed. Despite a series of legal twists and turns that disqualified two extremely popular figures, the two "revolutionary" candidates Hamdin Sibahi and Abd al-Monim al-Fatouh won a combined $40 \%$ of the popular vote (Kirkpatrick and Fahim 2012). While neither candidate made it to the second round, their success strongly suggests that the SCAF had failed to convince a large segment of Egyptian society that the revolutionary figures of Tahrir Square and their fellow demonstrators "did not represent” the Egyptian people (Fahim and Stack 2012).

\section{CONCLUSION}

It is still far too soon to decide the legacy of the Arab Spring and the January 25 Revolution, or the sustainability of the revolution's goals in Egypt, however, search data can clearly help political scientists track broad and cross-cutting societal developments as they unfold. A final question naturally emerges from this case study: what conditions facilitate the use of search data? This analysis suggests two main factors.

\section{Public Opinion and Internet Penetration}

The empowerment of public opinion and rapidly increasing levels of Internet penetration are the twin drivers that give search data its utility for political scientists. If Internet penetration levels are too low, or there is no meaningful way for society to engage in political action, search data is only marginally useful. For example, conditions in Mauritania, Sudan, and Yemen make it highly unlikely that search data from these countries would indicate anything beyond the behavior and interests of a handful of local elites. ${ }^{24}$

\section{Validation}

Skeptics are correct to treat online data and methods for analyzing it cautiously (Lynch 2011, see also Mellon 2013, this issue). Discrepancies between online and offline behavior do not mean that search data is somehow not "real," but that its contribution to any given research question depends on triangulation with surveys or complementary data sources like election results, which allow a researcher to iteratively test online behavior against offline outcomes. ${ }^{25}$ When public opinion is empowered, levels of Internet penetration are above a crucial threshold, and conventional measurements of public opinion are present political scientists should be able to use Google's "unintentional database" to explore the interests of a large section of society even in times of enormous social turmoil. Furthermore, the format and accessibility, speed of data collection, low cost, and volume of search data open new categories of research questions for exploration by social scientistsallowing researchers to quickly and efficiently test how widespread an intriguing anecdote actually is, or to objectively measure the online influence of public figures, ideas, and issues in real time.

\section{ACKNOWLEDGMENTS}

The author thanks, Sheena Chestnut-Greitens, Nelly Lahoud, Jonathan Mellon, and. Arie Perliger for their extensive comments and feedback. Thanks also to Joshua Goldstein, Najeeb Jarrar, and Ashraf Maklad for their suggestions pertaining to numerous technical and theoretical difficulties. Thanks to Jakob Earle and Muhab Wahby at the Danish Egyptian Institute for dialogue, Muhammad at Thawra Stats, and Craig Charney who all graciously explained their respective polling projects to me. Finally, several Egyptian friends weighed in at various times to keep me on track: Soha Gad, Waleed Nassar, and Noran Eid. All errors in this article are my own.

\section{NOTES}

1. One of the historic constraints to polling in the Arab world were that "controversial" or "politically sensitive" questions could not be asked in surveys, which all required official approval. It remains to be seen exactly how the revolution will influence these constraints. For a discussion 
of some of the challenges of polling in the region see Mark Tessler's "Introduction: Public Opinion Research in the Arab and Muslim Middle East" in Public Opinion in the Middle East 2011. Indiana University Press.

2. Defined by John Battelle as "the aggregate results of every search ever entered, every result list ever tendered, and every path taken as a result." And "a place holder for the intentions of humankind-a massive database of desires, needs, wants, and likes that can be discovered, supoenaed, archived, tracked, and exploited to all sorts of ends." "The Database of Intentions" http://battellemedia.com/archives/2003/11/ the_database_of_intentions.php

3. One significant difference from conventional statistical analysis is because raw numbers are not available to anyone outside of Google, it is impossible to construct a probability sample with search data. For a comprehensive discussion of the challenges of validation when using search data see Jonathan Mellon's contribution to this symposium.

4. It should be noted that in some countries in the Middle East, especially the Gulf States, Internet penetration levels meet or exceed those in the United States. Although there are linguistic and demographic challenges particular to these countries, this is a fascinating area for further study. See "Research Findings UAE" and "Saudi Arabia" (Insights MENA).

5. There is no consensus on a threshold of Internet connectivity that must be passed for search data to be of use. My assumption is that at least $20 \%$ of the population must have "regular" access to the Internet. At lower levels of Internet penetration, demographic discrepancies overwhelm the benefits of using Internet data to discuss nationwide issues-although they may still of course be useful for discussing specific subsections of society especially the middle class. This question of a minimum threshold is pertinent not just to Internet search, but even more so to discussions of social media, including Facebook and Twitter data.

6. Author interview, Cairo, 1/9/2012.

7. This advantage is noted even by those authors skeptical about the "predictive" power of search data. Goel et al. in their paper "What Can Search Predict?" state that in the "absence of other data sources, or where small improvements in predictive performance are material, search queries may provide a useful guide to the near future" (Goel et al. 2010).

8. For two examples of polling findings widely divergent from actual outcomes see Thawra Stats, "Too Close to Call." http://thawrastats.org/2011/ o3/18/318-survey-too-close-to-call/ and "Egyptian Elections" in the Brookings Institution annual "Arab Public Opinion Survey" (Slide 21) in which liberal and Islamic parties polled evenly when respondents were asked "what type of party they were likely to vote for." This divergence is found in other polls including those conducted by the International Peace Institute (IPI) and Gallup "Tahrir to Transition" (p. 18) which all underestimate or fail to capture the large amount of support for the Muslim Brotherhood's Freedom and Justice Party and the Salafi al-Nour party which combined won nearly $75 \%$ of the seats in the lower parliament.

9. Based on an estimate of slightly less than one Google search per day. According to the Nielsen data $44 \%$ of all Egyptians surveyed stated that they had Internet access (defined in the survey as logging in once in the last 30 days, surveys were conducted in urban areas). According to the CIA worldfactbook there are 56.5 million Egyptians over the age of 15 This would mean that $\sim 24,860$,ooo have "access" to the Internet. Respondents stated that they conducted an average of 6.26 searches per week. This suggests that Google in Egypt receives $\sim 22,374,000$ searches per day. While it seems likely that those who use the Internet more frequently are generating searches at a higher rate this cannot be established from the information provided by insightsmena.com.

10. Based on results from A.C. Nielsen survey 2011. Access is defined as "using the Internet in the last 30 days." See "About Insights MENA" http://www.insightsmena.com/en/about.

11. Due to Google's market penetration most studies safely assume that generalizations based on search data are valid about Internet users, but due to the demographic discrepancies discussed earlier these generalizations cannot be extended to other Egyptians.

12. See Koehler-Derrick, Gabriel, "Googling Egypt's Candidates" the Arabist blog, 5/24/12 for a failed attempt to use Search Data to make inferences about the results of the 2012 Egyptian Presidential election.

13. As Jonathan Mellon pointed out in his contribution to this symposium, the audience for various political figures can also have an impact. For example, Ron Paul was far more competitive in terms of online searches vis-a-vis the other candidates in the Republican primaries than he proved in any individual primary state. Polemical political figures, like Herman Cain, also exhibit a disproportionate influence online, presumably because many people searching for information about him were Democrats.
14. Hope, Bradley. 2011. "General: Egypt is Not Tahrir Square." The National 11/25/2011. http://www.thenational.ae/news/world/middle-east/generalegypt-is-not-tahrir-square See also, "Intikhabat misr bi maw'idiha wa hidou' bil-tahrir.” Al-Jazeera, 2011. http://www.aljazeera.net/news/pages/ 4023b41b-b1d6-4c62-98ea-69049645a852. November 24. The entire press conference can be found here: http://www.youtube.com/watch?v= $\mathrm{Z}_{1}$ HNBGRY10s the quote comes from approximately minute 47 in the video.

15. This section draws heavily on a short article coauthored with Joshua Goldstein, "Using Google Insights to Assess Egypt's Jasmine Revolution" 2011. The Sentinel, Combating Terrorism Center, March Issue.

16. Joseph Ripberger defines attentiveness as "the scarce resources-time and others-that citizens willingly dedicate towards thinking about publicly debated issues." See Ripberger, Joseph. 2011. "Capturing Curiosity: Using Internet Search Trends to Measure Public Attentiveness." Policy Studies Journal 39 (2): 239-591.

17. Again see Jon Mellon's contribution to this symposium for further discussion about the challenges of validating search data against more familiar research tools.

18. Polling from IPI suggests that by September 2011, $53 \%$ of Egyptians viewed continued protests as "unnecessary disruptions."

19. See an interview with Yousri Abu Shadi for a long discussion based around El Mallah's argument. http://www.youtube.com/watch?v= JdUiuzpE3zw A December 4 interview with Mamdouh Abd al-Haq uses basically the same language: http://www.youtube.com/watch?v= CJLbkfDuRqE The largest Facebook group that explicitly repackages the General El Mallah's statement had approximately 858 members as of September 2012. "Misr Mish Midan al-Tahrir Misr Akbar bi Kiteer" (Egypt is not Tahrir, Egypt is so much more).

20. Prominent Salafi Sheikh Muhammad Hasan went further claiming that it was a "foreign plot" and a spokesman for the Muslim Brotherhood compared it to the "foreign fingers who failed in trying to control the Egyptian revolution." See http://www.youm7.com/News.asp? NewsID $=592531$.

21. Clips from both poets are widely available on YouTube. For example see this performance of "Mashad Ra'sin min Maydan Tahrir" by Hisham al-Gakh (viewed over 1.5 million times). https:/www.youtube.com/ watch?v=Jcuo-MMpSI8 A similarly "revolutionary" poem from Qatamish can be found here: https://www.youtube.com/watch?v= rk4XuN16xtg.

22. A comparison of the search terms "Israel" and "Palestine" in Egypt illustrates this point nicely. While spikes in searches around key events in May 2004 and January 2009 suggest occasionally high degrees of correlation between these two search terms, the volume of search overall is much higher for the term "Palestine." This is not to suggest that Egyptians don't feel passionately about Israel, simply that they tend to be much more likely to search for information about the conflict using a term that they associate with, rather than one they don't.

23. This in sharp contrast with searches for the names of specific individuals killed in these incidents. For example, searches for "Emad Effat" (a sheikh from al-Azhar killed in the protests outside of parliament) and "Meena Daniel" (a protestor killed at Maspiro) were constrained to Cairo and Alexandria.

24. Reliable Internet penetration levels are not available for these countries.

25. Of course these discrepancies can often be an interesting area of exploration. See for example Charles Hirschkind's study of Khutba (religious speeches) on YouTube. "Experiments in Devotion Online: The YouTube Khutba." International Journal of Middle East Studies 44 (2012), 5-21.

\section{REF EREN CES}

'Abd al-Gawad, Gamal, Ahmed Nagi Qamha, Sobhi 'Asila, et al. 2012. "Istala' al-Barometer al-'Araby." Egypt Country Report, Arab Barometer. http:// www.arabbarometer.org/arabic/reports/ABII/countyreportyegypt.pdf.

Abu Dhabi Gallup. 2011. "Egypt from Tahrir to Transition.” (See slide 18). http://www.gallup.com/file/poll/148133/Egypt_Tahrir_to_Transition_ Deck_Final_June_2011.pdf.

al-Ahram Online. 2012. "Abul-Fatouh Dips, Moussa Holds Steady in Ahram Presidential Poll.” Ahram Online, May 14. http://english.ahram.org.eg/ NewsContent/36/122/41592/Presidential-elections-/Presidential-electionsnews/AbulFotouh-dips,-Moussa-holds-steady-in-Ahram-pres.aspx.

Asher, Herbet. 2007. Polling and the Public: What Every Citizen Should Know, 7 th ed. Washington, DC: Ohio State University/Congressional Quarterly Press. 
Battelle, John. 2003. “The Database of Intentions.” John Battelle's Search Blog. http://battellemedia.com/archives/2003/11/the_database_of_ intentions.php.

Carneiro, Herman Anthony, and Eleftherios Mylonakis. 2009. "Google Trends: A Web-Based Tool for Real-Time Surveillance of Disease Outbreaks." Clinical Infectious Diseases 49 (10): 1557-64. http://www. ncbi.nlm.nih.gov/pubmed/19845471.

Choi, Hyunyoung, and Hal Varian. 2009. "Predicting the Present with Google Trends.” http://static.googleusercontent.com/external_content/untrusted dlcp/www.google.com/en/us/googleblogs/pdfs/google_predicting the present.pdf.

Cowie, Jim. 2011. "Egypt Leaves the Internet." Renesys. http://www.renesys. $\mathrm{com} / \mathrm{blog} / 2011 / 01 /$ egypt-leaves-the-Internet.shtml

Danish Egyptian Dialogue Institute (DEDI) and Al-Ahram Center for Political and Strategic Studies. 2011. "Poll Releases 1-6." http://dedi.org.eg/ project/egypt-elections-projects/

Fahim, Kareem, and Liam Stack. 2012. "Some Disdain Both Options in Egypt's Narrowed Race.” New York Times, May 26. http://www.nytimes. com/2012/05/27/world/middleeast/some-in-egypt-disdain-both-candidates. html.

Ginsberg, Jeremy, Matthew Mohebbi, Rajan Patel, Lynnette Brammer, Mark Smolinski, and Larry Brilliant. 2009. "Detecting Influenza Epidemics Using Search Engine Query Data.” Nature 457: 1012-14.

Global Stats. 2012. "Top 5 Search Engines in Egypt from July 2008 to Decem ber 2012." http://gs.statcounter.com/\#search_engine-EG-monthly-200807201212.

Goel, Sharad, Jake Hofman, Sébastien Lahaie, David Pennock, and Duncan Watts. 2010. "Predicting Consumer Behavior with Web Search." Proceedings of the National Academy of Sciences, Early Edition. www.pnas.org/cgi/ doi/10.1073/pnas.1005962107.

Goldstein, Joshua, and Gabriel Koehler-Derrick. 2011. "Using Google Insight to Assess Egypt's Jasmine Revolution." Combating Terrorism Center Sentinel 3 (4): 4-9.

Google. "Zeitgeist 2011." http://www.googlezeitgeist.com/en/.

Granka, Laura. 2010. "Measuring Agenda Setting with Online Search Traffic: Influences of Online and Traditional Media." Annual Meeting of the American Political Science Association. http://laura.granka.com/ papers_talks.html.

Greitens, Sheena Chestnut. 2013. "Authoritarianism Online: What We Can Learn from Internet Data in Nondemocracies." PS: Political Science and Politics 46 (2), this issue.

Hassanpour, Navid. 2011. "Media Disruption Exacerbates Revolutionary Unrest: Evidence from Mubarak's Natural Experiment.” Annual Meeting of the American Political Science Association. http://papers.ssrn.com/sol3/ papers.cfm?abstract_id=1903351.

InsightsMena.com. 2011. http:/www.insightsmena.com/en/\#!place= category $\&$ cat $=$ Internet + Usage \&qid $=$ Internet + Usage + Rates \&filter $=\mathbf{2 0 1 1}$,Egypt

International Peace Institute. 2011. "Public Opinion in Egypt." http://www. ipinst.org/images/pdfs/ipi-egyptpoll-june2011.pdf.

King, Gary, Jennifer Pan, and Margaret Roberts. 2012. "How Censorship in China Allows Government Criticism but Silences Collective Expression." http://gking.harvard.edu/files/censored.pdf.
Kirkpatrick, David, and Kareem Fahim. 2012. "Egypt Race Pits Aide to Mubarak against Islamist.” New York Times, May 25th. http://www. nytimes.com/2012/o5/26/world/middleeast/egypt-presidential-electionrunoff.html?pagewanted $=$ all.

Lynch, Marc. 2011. "The Limits and Promise of Online Challenges to the Authoritarian Arab State." Perspectives on Politics 9 (2): 301-10.

Ministry for Communications and Information Technology (MCIT). 2012. "ICT Indicators in Brief." http://mcit.gov.eg/Upcont/Documents/ Publications_292201200o_Eng\%2oFlyer.pdf.

Mellon, Jonathan. 2011. "Search Indices and Issue Salience: the properties of Google Trends as a measure of Issue Salience." http://www.sociology. ox.ac.uk/documents/working-papers/2011/swp1101.pdf.

Mellon, Jonathan. 2013. "Where and When Can We Use Google Trends to Measure Issue Salience?” PS: Political Science and Politics 46 (2), this issue.

Newig, Jens. 2004. "Public Attention, Political Action: the Example of Environmental Regulation." Rationality and Society 16: 149-90.

Pew Global Attitudes Project. 2011. "Egyptians Embrace Revolt Leaders, Religious Parties and Military, As Well." http://www.pewglobal.org/files/2011/ 04/Pew-Global-Attitudes-Egypt-Report-FINAL-April-25-2011.pdf.

- 2010. "Most Embrace a Role for Islam in Politics Muslim Publics Divided on Hamas and Hezbollah." http://www.pewglobal.org/files/2010/ 12/Pew-Global-Attitudes-Muslim-Report-FINAL-December-2-2010.pdf.

Ripberger, Joseph T. 2011. "Capturing Curiosity: Using Search Trends to Measure Public Attentiveness." Policy Studies Journal 39 (2): 239-59.

Scharkow, Michael, and Jen Vogelgesang. 2011. "Google Insight for Search: A Methodological Innovation in the study of the Public Agenda?" International Journal of Public Opinion Research 23 (1): 104-13

Scheitle, Christopher. 2011. "Google's Insights for Search: A Note Evaluating the Use of Search Engine Data in Social Research." Social Sciences Quarterly 92 (1): 285-95.

Shadid, Anthony. 2011. "Egypt Military Tries to Woo Wider Public to Keep Power." New York Times, November 25. http://www.nytimes.com/2011/11/ 26/world/middleeast/egypt-military-tries-to-woo-wider-public-beyondprotesters.html?pagewanted $=$ all.

Shatz, Adam. 2012. "Whose Egypt?" London Review of Books 34 (1): 15-17.

Stephens-Davidowitz, Seth. 2012. "The Effects of Racial Animus on a Black Candidate: Using Google Search Data to Find What Surveys Miss." (Draft)

Telhami, Shibley. 2011. "2011 Arab Public Opinion Poll.” (See Slides 20 \& 21.) http://www.brookings.edu/research/reports/2011/11/21-arab-publicopinion-telhami.

Thawra Stats. 2011. "Min ya'thr fi al-ray al-'aam al-Misri?" http://thawrastats. files.wordpress.com/2011/o4/influencers-final.jpg

Younis, Ahmed, and Mohammed Younis. 2011. "Most Egyptians Believe Continued Protests are Bad for Country." Gallup Polling. http://www.gallup. com/poll/151001/egyptians-believe-continued-protests-bad-country.aspx.

. 2012. "Egyptians Expect Military to Hand Power to Elected Gov't." Gallup Polling. http://www.gallup.com/poll/152177/egyptians-expectmilitary-hand-power-elected-gov.aspx. 